\title{
What is Ontology? A Dialogue
}

Adelaide, a graduate student in philosophy, is sitting in a café, lost in thought, mindlessly tapping softly on her espresso cup. Sydney, a graduate student in chemistry, is sitting several tables away, immersed in a book he's reading. As another patron takes off, they suddenly notice each other.

Sydney: Hey, Adelaide! What's up?

Adelaide: Hey... What are you doing here?!

Sydney: Just reading. And you?

Adelaide: What are you reading?

Sydney: A play by Chekhov - "Uncle Vanya."

Adelaide: Nice. I'm just sitting here thinking...

Sydney: What about?

Adelaide (smiling): Ontology...

Sydney (raises his eyebrows, walks over to Adelaide's table and grabs a chair): What's ontology?

Adelaide (grimaces): Oh man... it's complicated.

Sydney (sunny): Try me.

Adelaide: Well, it's a branch of philosophy. The common definition is that it's the "theory of what there is."

Sydney: Isn't everything a theory of what there is? I mean, when physicists discovered the Higgs boson, they learned something about what there is, no? Does that count as ontology?

Adelaide: Hmm, no, it doesn't. I suppose the more accurate thing to say is that ontology is about what there is at the highest level of abstraction.

Sydney (in a skeptical tone of voice): What does that mean?

Adelaide: Well, think of it this way. Look at that guy's dog (points at someone at the café with a dog sleeping in his lap). What is it, a beagle? 
Sydney: Yeah, looks like a beagle...

Adelaide: Well, a beagle is a kind of dog, which is a kind of canine, which is a kind of mammal, which is a kind of animal. Now imagine the complete tree of all the animal kingdom. The trunk reads "animals," and the tree then splits into branches and subbranches.

Sydney: Okay.

Adelaide: Now focus on the very first split in the tree. That first split gives you the kinds of animals there are at the highest level of abstraction.

Sydney: The vertebrates and the invertebrates.

Adelaide: If you say so.

Sydney: It's definitely vertebrates and invertebrates.

Adelaide: Okay, then vertebrates and invertebrates are the kinds of animals there are at the highest level of abstraction. Now let's switch from animals to everything there is, the complete "kingdom of being." And now imagine we make a complete tree of the kingdom of being the way zoologists make a complete tree of the animal kingdom.

Sydney (eyes lit up): The great "tree of being"... That's pretty cool...

Adelaide (pleased by the reception): I know, right? And the very first split in that tree gives you the different categories of beings there are "at the highest level of abstraction."

Sydney (reflectively): Interesting... So ontology is some kind of classification project?

Adelaide: Hmm, not really. I'm just trying to explain what "what there is at the highest of abstraction" means. Once you get clear on which categories of things there are at the highest level of abstraction, then the real work starts - the work of studying these categories.

Sydney: But the first step is to get clear on which categories need to be studied - is that what you're saying?

Adelaide: Right.

Sydney: And that means that just like the zoologists start their tree with a split between vertebrates and invertebrates, the ontologists have to find the most basic distinction between two categories of things.

Adelaide: Well, you say "two," but zoologists didn't start out assuming that the first split has to be between two kinds of animals - could be three, four, or whatever. Same with ontology.

Sydney: Right. (Brief pause.) But wait. When people play "animal, vegetable, or mineral" are they doing ontology? I mean, that's supposed to divide things into three basic categories. 
Adelaide (smiling faintly): Okay, the word "things" is not ideal here - it makes it sound like we're only talking about physical objects. But reality may contain something other than physical objects.

Sydney: Like what?

Adelaide (reflects a moment): Let me ask you this. How was your flight to New York last month?

Sydney: It was fine. What does that have to do with anything?

Adelaide: Your flight was fine. So, your flight really happened. It's part of "Re-a-li-ty." But it's not a physical object. You can't touch a flight like you can touch this table here.

Sydney: You can touch the airplane.

Adelaide: Yes, you can touch the airplane that's doing the flying; but you can't touch the flying that the airplane does.

Sydney (smiles appreciatively): I guess so. And you're thinking, that shows that the flight is not a physical object?

Adelaide: Or at least suggests it. It's sort of a symptom of the fact that a flight is not an object in the same sense that tables and cats are objects. But my point is that a flight is still something - it's not nothing.

Sydney: So what is it?

Adelaide: An event?

Sydney: Hmm... Okay. So what's your point?

Adelaide: My point is that events are neither animals, nor vegetables, nor minerals. And more generally, that a classification of physical objects is not the same as a classification of everything there is.

Sydney (getting it): Right, right... So the classification of objects into animal, vegetables, and minerals, even if we took it seriously, would not be the first split in the "tree of being."

Adelaide: Exactly.

Sydney: So what else do ontologists like to include in the first split, beyond the objects and events?

Adelaide: Maybe there will be a branch for properties, like the roundness of this table or the quickness of your flight; maybe a branch for facts, like the fact that this table is round or that the flight was quick; maybe some other branches.

Sydney (recapping in a hesitant tone of voice): Objects, events, properties, facts... and maybe some other stuff? That's what you're suggesting? 
Adelaide (pouncing): You see, that's a very high level of abstraction!

Sydney: Sure is. When you were talking about the zoological classification of animals, I thought the ontological classification of things will cover both animals and objects that aren't animals. But now I see it's actually even more abstract than that - "object" is itself just one branch in the tree of being. There will be branches with completely different kinds of things.

Adelaide (nods): Right. But like I said, the word "things" is not great for our purposes. That's why I prefer using the highfalutin word "beings" - in case part of "the tree of being" isn't things in the sense of physical objects.

Sydney: Hmm, I don't know about this - the word "being" isn't that great either. I mean, nobody would say that my flight to New York was a being. That still sounds like we're talking about objects...

Adelaide: Yeah, you're right. Sometimes philosophers use the word "entity" for this maximally generic category that covers everything.

Sydney: Eh, I don't think anyone would say my flight to New York was an entity either. Maybe language doesn't have a word for this, because it only has words for dividing reality in some way?

Adelaide: You know, I think you might be right. We basically need to invent a new word a word to talk about the trunk of our ontological tree, before the first split. I had a friend who coined the word "ontoid" for this.

Sydney (laughs): So my flight to New York is not a being, but it's "an ontoid." I like it! (Brief pause.) Mind you, if we're trying to talk about everything that exists, whatever it turns out to be, why not use the word "existent"?

Adelaide (nods with increasing conviction): You know, that's not bad, actually!

Sydney (pleased): Thank you.

Adelaide: It sounds a bit weird to say that your flight to New York is an existent, but much less weird than to say that it's a thing or an "entity."

Sydney: I agree.

Adelaide (nods pensively for a while): Well, anyway... What I'm saying is that ontology is the theory of what there is at the highest level of abstraction, which means it's about the categories of existents that show up at the very first split in the tree of being.

Sydney: Got it. Pretty interesting...

Adelaide: That's what I think...

(They both nod, look at each other, look around contemplatively.)

Sydney: But there's something I don't get. 
Adelaide: Okay.

Sydney: The zoologist is not interested in just the first split in the tree of the animal kingdom. Their job is to produce the whole tree. Why is the ontologist only interested in the first split?

Adelaide: I guess the idea is that the higher branches of the tree are already taken care of by the sciences. You know, the tree of the animal kingdom is strictly speaking a subtree of the tree of existents. And in botany you have a classification of plants, in chemistry you got the periodic table of elements - I don't need to tell you about that... (They exchange smiles.) These are all essentially fragments of the great tree of being.

Sydney: Still... Who says that the sciences will take care of all the parts of the tree of being other than the very first split?

Adelaide: You're totally right. They almost certainly won't. So maybe we should say more exactly that ontology takes care of the first few splits in the tree - just as far as needed until specific sciences take over.

Sydney: So what you're saying is that ontology is interested in the categories of existents at the highest levels of abstraction, not the highest level.

Adelaide: "Levels" in the plural. Yes, that's the thing to say. And what does "highest levels" mean? It just means all the levels that are too abstract for any specific science to deal with. They are what philosophers sometimes call "topic-neutral" categories.

Sydney: Nice. So after the first split in the tree of being, there will be some branches that will also split again, and these will split into smaller branches, and so on and so forth. And this series of splits will still be the ontologist's business - until someone else makes it their business. Is that what you're thinking?

Adelaide: That's what I' $m$ thinking. What do vertebrates divide into? Is that where the tree of the animal kingdom divides into mammals, birds, reptiles, and all that?

Sydney: And amphibians and fish. Yes.

Adelaide: So that's the second-to-highest level of abstraction in categories of animals. And there's going to be a second-to-highest level of abstraction in categories of existents in general, and that's probably going to still be too abstract to interest anybody other than an ontologist.

Sydney: So, do ontologists actually discuss the different subdivisions at the second-tohighest level of abstraction?

Adelaide: They definitely do. For example, they divide objects into concrete objects and abstract objects, they divide properties into intrinsic properties and extrinsic properties, and so on.

Sydney: Okay, I don't really know what all these words mean, but I get the point. What's weird to me in all this is the question of objectivity. 
Adelaide: What do you mean?

Sydney: Well, you're talking like there's this objective "tree of being" out there and science and ontology are going to discover it - map it out like you map out the DNA or something. But who says we don't just categorize things depending on what's more convenient for us, what we care about - that kind of stuff.

Adelaide (nods energetically): You're absolutely right. It's an issue, and there is a debate in meta-ontology about this. (Sydney rolls his eyes ironically.) Do existents divide into categories in and of themselves, or only relative to certain facts about the cognitive system and the interests of whoever is doing the categorizing?

Sydney: "Meta-ontology"?

Adelaide: Yes, meta-ontology! If ontology is the study of what exists at the highest levels of abstraction, meta-ontology is the study of the study of what exists at the highest levels of abstraction. That's not so weird.

Sydney: I guess not. So one question in meta-ontology is whether there is one objectively true categorization of existents or many equally legitimate ways to categorize existents and we just choose whichever suits us best for whatever reasons. Is that what you're saying.

Adelaide: Well, let me ask you something. How does it work in chemistry? Do chemists debate whether the periodic table is objective or not?

Sydney (nods): Interesting point. The answer to that is No, there's no such debate in chemistry. Mind you, the elements in the periodic table are distinguished by the number of protons they have in their nucleus. And that's a hard objective fact - that sometimes there are 4 protons and sometimes are 7 , and 4 is not the same as $7 \ldots$

Adelaide: So, there might be similar hard facts about a difference between objects and events, for example. It's just that they're going to be much more high-level, much more abstract differences. Or it might be that it's all relative to our interests or whatever.

Sydney: So... what do we do?

Adelaide: Look, if it turns out that the whole categorization of existents at the highest levels of abstraction reflects our own deepest cognitive tendencies or needs, it's still interesting to know how our cognitive system naturally carves up reality at the most basic level. And if it turns out that ontologists are discovering the objective structure of reality, even better! (Looks at him.) My point is: it's a worthwhile intellectual endeavor either way.

Sydney: Alright... Hey, it's your job, if you're cool with it either way, who am I to complain...

Adelaide: Look, I prefer it if it turns out I'm figuring out the objective structure of reality. But I think you don't need to settle this meta-ontological question to find value in ontology proper. 
(Lull. Both Adelaide and Sydney are observing with some satisfaction the aforementioned beagle. Adelaide smiles at the Beagle owner, who is leaving the café. Sydney scribbles something down on a napkin, then slides it under Adelaide's nose.)

Sydney: Look what I've made.

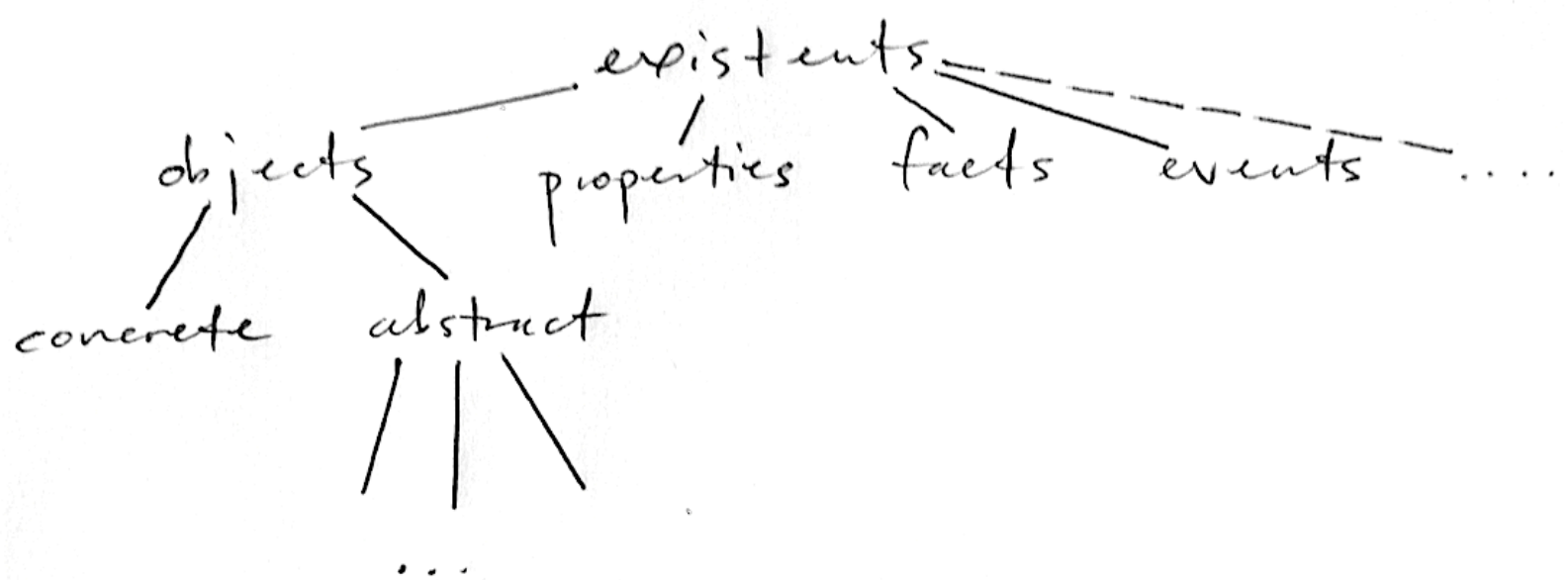

Adelaide (smiling): Hey, that's cool man.

Sydney: I know, right? Mind you, I don't see why this is not just a classification project.

Adelaide (smiling): Well, first you need to get clear on what categories of things - I mean, of existents - there are at the highest level of abstraction. But the main business of ontology is to study these categories. "Study" doesn't just mean identifying the ontological categories; it means also giving a theory of what they are - of their nature.

Sydney: I see. So you could say that ontology has two parts: one identifying these ontological categories and one explaining what they are.

Adelaide: I guess so, though in practice it goes together - because once you distinguish between objects, properties, facts, etc., you still need to say something about what distinguishes them from each other. And that requires having a rudimentary idea of their nature.

Sydney: Okay, but what does it mean to study the nature of a category? What do you actually $d o$ ? If you send me home now and tell me "do me a favor, study the nature of events for me this week," I will have no idea what to do.

Adelaide (faint smile): Okay, by the "nature" of a category I mean what makes it the category it is and distinguishes it from other categories. What makes an event an event and not an object? What makes an object an object and not a property?

Sydney: It's all so abstract. 
Adelaide: Well, that's the nature of our subject matter, my friend. The way I see it, there are two very different kinds of theories that you can give about the nature of some ontological category. The simplest way is to account for the existents of one category in terms of combinations of existents from another categories.

Sydney: You mean like in chemistry? (Adelaide proffers a gesture meaning roughly "say more please.") In chemistry, the way you give a theory of some molecule is you say what atoms it's made out of and what type of chemical bond is holding them together.

Adelaide: Yes, I guess this kind of ontological theory works in a similar way. Here we show that existents of some ontological category $\mathrm{X}$ are somehow "built out of" existents of ontological category $\mathrm{Y}$, or categories $\mathrm{Y}$ and $\mathrm{Z}$.

Sydney: Give me an example.

Adelaide: Okay, there's a theory that an object is just a bundle of properties. (Detecting lack of appreciation in Sydney.) This table here, for example - what is it? If you make a complete list of all the properties the table has - being round, bring brown, being hard, weighing such-and-such - you've captured the complete nature of it as an object. There's nothing more to it than all the properties it's got.

Sydney: What else would there be to it? I mean, we're assuming we've listed all of the table's properties, right?

Adelaide: Yes, but some ontologists insist that in addition to these properties, there must be something that has the properties - and that's what the table actually is. But whatever. My point is just that the theory that objects are just bundles of properties - it's called the bundle theory, by the way - tries to account for existents of one category, objects, in terms of existents from another category.

Sydney: Properties.

Adelaide: Right.

Sydney (after a brief pause): So according to this "bundle" theory, the "nature" of objects is to be bundles of properties. Is that the idea?

Adelaide: Exactly. Notice that if this theory is true, then a complete theory of the world can be stated without even mentioning objects - all you'll need to mention is properties and their bundling. Which makes ontologists happy.

Sydney: Why does it make them happy?

Adelaide: Because it's considered a major plus for an ontological theory if it can account for the whole of reality with the absolute minimum number of posits necessary. When you account for existents of category $X$ in terms of combinations of existents of category $Y$, you show that $X$ in some sense reduces to $Y$, or is grounded in $Y$, or is "nothing over and above" $Y$. So you've removed Xs from your list of existents it's absolutely necessary to mention in a complete theory of the world. You made your theory "leaner," more parsimonious and more unified. 
Sydney: But wait. This bundle theory - it only helps us understand the nature of objects if we already understand the nature of properties. If we don't know what a property is, how does it help to be told that an object is a bundle of those? Or am I missing something?

Adelaide (smiling in appreciation): No, no, you're totally right.

Sydney: But now suppose you tell me that properties are bundles of facts or whatever. Still, that would help me understand what properties are only if I already understand what facts are. But this can't go on forever. At some point you need to understand the nature of some category of existents independently of understanding any other category of existents. (Peeps apprehensively at Adelaide.) Does that make sense?

Adelaide (nodding): Totally. That's why I said there were two types of theories about the nature of ontological categories. You need the second type of theory for ontological categories that you don't account for in terms of other ontological categories.

Sydney (excitedly): That's what I'm saying!

Adelaide: I know, I'm agreeing with you. At some point, you get to ontological categories that are fundamental - you can't account for them in terms of other, more basic categories. Those are the ontologically primitive categories.

Sydney: "Ontologically primitive." I like that... But how can you give a theory of them if you can't explain them in terms of anything else?

Adelaide: You have to find a different style of theory - a theory that explains these ontological categories in their own right, so to speak.

Sydney: Like what?

Adelaide: Usually what happens is that once you have your list of primitive categories, you try to think what's the basic thing that distinguishes them - some important dimension along which they differ from each other.

Sydney (squinting): Give me an example.

Adelaide: For example, suppose you got the view that the two primitive categories are objects and properties.

Sydney: I thought you said objects are just bundles of properties.

Adelaide: According to the bundle theory they are. But suppose you don't buy the bundle theory. Suppose you think that objects are special existents that have properties, but are not themselves just collections or bundles of properties. And you also don't think that you can account for properties in terms of some other categories. You need to mention both objects and properties in a complete theory of the world. I'm saying "suppose"...

Sydney (cooperatively): Okay; I'm supposing it. 
Adelaide: So now you need to account for objects and properties without explaining either in terms of the other. You need some kind of non-reductive account of each.

Sydney: "Non-reductive"? That's what people call this kind of account?

Adelaide: Let's call it that. The idea is that you don't reduce objects to properties and you don't reduce properties to objects.

Sydney: And you don't reduce both of them to some third thing.

Adelaide: Right. So here's a "non-reductive" theory you might give: objects are concrete existents, in that they exist in space-time, whereas properties are abstract existents, in that they exist outside space-time.

Sydney: Why are properties outside space-time? Isn't the roundness of this table right here?

Adelaide: Well, let's distinguish between the roundness of this or that thing and roundness as such. Roundness as such is a property, the roundness of this table here is a propertyinstance. The theory I'm talking about says that roundness as such is outside spacetime. It's a theory about the difference between objects and properties, not about the difference between objects and property-instances.

Sydney: Man, this is all pretty complicated.

Adelaide: Don't worry about it - I'm not saying it's a true theory. Actually I'm pretty sure it's way too simplistic. But I'm just giving an example of a "non-reductive" theory of ontological categories.

Sydney (nods): Right. And this theory says basically three things: (a) objects are existents that exist in spacetime; (b) properties are existents that exist outside spacetime; (c) all other ontological categories can be accounted for in terms of objects and properties.

Adelaide (with appreciation): Exactly.

Sydney: But really, you think this theory is false. You're just giving it as an example of a theory that has the right shape for an ontological theory that doesn't reduce Xs to Ys.

Adelaide: Ehh-xactly!

Sydney: But why is it false? It kind of makes sense, when you think about it...

Adelaide: Well, I just think it's simplistic to say "inside spacetime" and "outside spacetime." For one thing, "outside of" is itself a spatial expression, so strictly speaking it makes no sense to say that something is "outside of" space itself.

Sydney: Oh yeah, you're totally right about this.

Adelaide: But it's true that most theories that try to characterize ontological categories nonreductively end up doing it in terms of the relationship that existents from those categories have to space and/or time. The way things exist in space and time is like their special "mode of being." 
Sydney: Oh boy. "Mode of being"... Do I even want to ask?

Adelaide (throws a sympathetic hand in the air): Forget "mode of being."

Sydney: Forgotten.

Adelaide: The point is that a non-reductive account of an ontological category will usually identify some distinctive way existents from that category relate to space or time. This is the kind of account we usually give for ontologically primitive categories.

Sydney (reflecting a little): But for non-primitive categories, we just explain them in terms of existents from other categories - right?

Adelaide: Right. The general architecture of a complete ontological theory is like this. First, we offer a categorization of existents at the highest level - I mean, levels - of abstraction. Second, we account for the nature of some of these categories in terms of other, more fundamental categories - until you get to the fundamental categories, the ontologically primitive ones. Third, we account for the nature of the fundamental categories in terms of some very general features that all and only members of that category have - features that often have to do with their relationship to space and time.

(Sydney nods thoughtfully. Adelaide smiles faintly. A lull in the conversation ensues. Sydney checks his phone, writes something. Adelaide sits back and looks around her at all the new people in the café.)

Sydney: Okay, I have to go. So this is what ontologists do when they wake up in the morning - look up what stage they are in this process and push on?

Adelaide: Not really... In real life ontologists just weigh in on all sorts of more specific, more local debates. What I'm giving you is a "rational reconstruction" of what the overall project is. What I'm saying is, almost all of the local debates ontologists weigh in on feed, directly or indirectly, into the project I just described.

Sydney: What do you mean "feed into"?

Adelaide: Well, they are either about whether you can account for some type of existent in terms of other ones or about the basic features that distinguish existents from different ontological categories. And then there are also debates about the nature of space and time themselves. In the last couple of decades, most of the hottest debates have been about the way material objects exist in space and time.

Sydney: Well, anyway, this ontology business is pretty interesting.

Adelaide (pleased): That's what I think! It's like the chemistry of everything.

Sydney: It's like the everything of everything!

Adelaide (even more pleased): Ha! Well I'm glad you like it.

Sydney (stands up): You want to meet up next week to discuss which monocategorial ontology is the most plausible? 
Adelaide (enthused): Happily!

Sydney: Great, see you next week - same place, same time?

Adelaide: Sure. This café can be our mode of being in space and time when we do ontology...

Sydney: Ha!

(Sydney laughs as he leaves, then waves good-bye one last time. Adelaide smiles back.

After looking around some, she takes out a notebook, leafs through to a specific page, and starts writing furiously.)

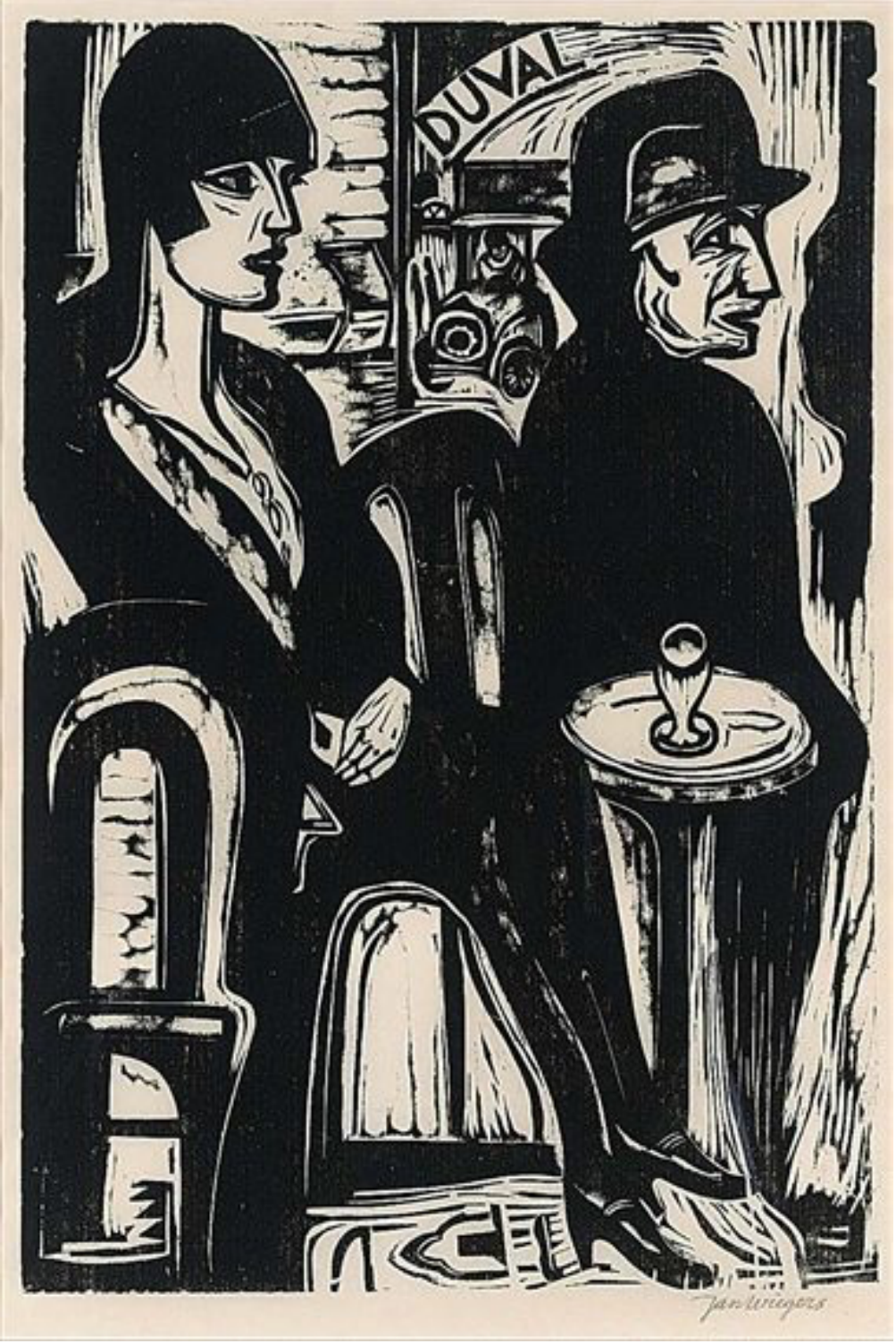

